\title{
Holo-TFIID supports transcriptional stimulation by diverse activators and from a TATA-less promoter
}

\author{
Qiang Zhou, Paul M. Lieberman, Thomas G. Boyer, and Arnold J. Berk ${ }^{1}$ \\ Department of Microbiology and Molecular Genetics, Molecular Biology Institute, University of California, Los Angeles, \\ California 90024-1570 USA
}

\begin{abstract}
Transcription factor IID (TFIID) binds to TATA boxes, nucleating the assembly of initiation complexes containing several general transcription factors and RNA polymerase II. Recently, TFIID was shown to be a multisubunit complex containing a TATA box-binding polypeptide (TBP) and several tightly associated polypeptides (TAFs), which are required for transcriptional stimulation by activator proteins. Here, we report the development of a human cell line expressing an epitope-tagged TBP and the immunopurification of a native, high-molecular-weight form of TFIID that supports transcriptional stimulation by several different classes of activation domains. Recovery of basal and activated TFIID transcriptional specific activity was close to $\sim \mathbf{1 0 0} \%$. Electrophoretic mobility-shift analysis demonstrated a single major DNA-protein complex. This holo-TFIID contains TAFs of $\sim 250,125,95,78$, and $50 \mathrm{kD}$ and sediments at 17S. Holo-TFIID produced an extended footprint over the adenovirus major late promoter TATA box and initiator sequence and supported transcriptional activation from a promoter lacking a TATA box. These results lead us to hypothesize that a single multisubunit TFIID protein supports transcriptional stimulation by diverse activation domains and from a TATA-less promoter.
\end{abstract}

[Key Words: TFIID; TATA box; transcriptional activation; TATA-less promoter]

Received June 11, 1992; revised version accepted July 21, 1992.

Transcription factor IID (TFIID) has a central function in transcription initiation by RNA polymerase II. On promoters containing a TATA box, TFIID binds to the TATA box (Sawadogo and Roeder 1985; Nakajima et al. 1988 ) and initiates the ordered assembly of several other general transcription factors and RNA polymerase II into a large multiprotein initiation complex (Van Dyke et al. 1988; Buratowski et al. 1989; Cortes et al. 1992). TFIID is also necessary for transcription from a promoter lacking a TATA box (Pugh and Tjian 1990, 1991; Smale et al. 1990). A cDNA encoding a TATA box-binding polypeptide (TBP) from human cells was isolated (Hoffman et al. 1990; Kao et al. 1990; Peterson et al. 1990), but the protein expressed from this cDNA performs only some of the functions of TFIID partially purified from human cells and has significantly different physical properties from TFIID activity. TBP participates in transcription initiation from a promoter containing a TATA box in conjunction with the other general transcription factors and RNA polymerase II, but the reaction shows very limited response to regulatory transcription factors that strongly stimulate transcription in reactions with the partially purified TFIID protein fraction (Hoffman et al. 1990; Pugh and Tijian 1990). The cloned TBP produces an

\footnotetext{
${ }^{1}$ Corresponding author.
}

$\sim 20$-bp DNase I footprint centered over the adenovirus 2 major late promoter TATA box, whereas partially purified human TFIID produces a footprint that extends over the transcription start site as far as +35 (Sawadogo and Roeder 1985; Nakajima et al. 1988). Finally, while the cloned TBP polypeptide is only $38 \mathrm{kD}$, TFIID activity from mammalian cells has a sedimentation coefficient of $\sim 17$ S (Samuels et al. 1982) and a Stokes radius consistent with an assymetric molecule of $\sim 750 \mathrm{kD}$ (Conoway et al. 1991).

The reason for these discrepencies between the functional and physical properties of TBP and TFIID is that TFID is composed of TBP plus multiple tightly associated polypeptides, called TAFs (Dynlacht et al. 1991; Tanese et al. 1991). Recently, it was shown that human TBP is also a subunit of the RNA polymerase I transcription factor SLl (Comai et al. 1992) and that TBP is required for all transcription by RNA polymerase III (Cormack and Struhl 1992; Schultz et al. 1992; White et al. 1992). Thus, TBP participates in specific transcription initiation by each of the three eukaryotic RNA polymerases (Sharp 1992). In this paper we use the term TFIID to refer to the complexes of TBP and associated polypeptides involved in transcription by RNA polymerase II as opposed to TBP-containing complexes required for transcription by RNA polymerases I and III. 
In the work demonstrating that human TFIID is a multisubunit protein in which TBP is only one subunit, $\geqslant 20$ polypeptides were identified as possible TFIID TAFs (Tanese et al. 1991). Reconstituted TFIID assembled from isolated TAFs and recombinant TBP responded to some activator proteins but not others (Dynlacht et al. 1991; Tanese et al. 1991). These observations raised the possibility that there might be a number of different TFIID complexes containing distinct sets of TAFs, with different TFIID complexes mediating transcriptional stimulation by different sets of activator proteins (Pugh and Tjian 1992; Sharp 1992). In this paper we describe the purification of what appears to be a single major TFIID complex from HeLa cells. This complex is sufficient for transcriptional stimulation by several different activator proteins with distinct classes of activation domains. In contrast to TBP, the isolated TFIID complex also supports transcription from a promoter lacking a TATA box.

\section{Results}

\section{Autoregulation of TBP concentration}

To purify the multisubunit TFIID complex with high transcriptional specific activity, we utilized the epitopetagging method of Field et al. (1988). A gene encoding an epitope-tagged TBP (eTBP) was stably transformed into HeLa cells using retrovirus vectors. Clones of transformed HeLa cells expressed varying levels of eTBP (Fig. 1, left). A similar blot was analyzed using a polyclonal rabbit serum raised against human TBP, which recog-

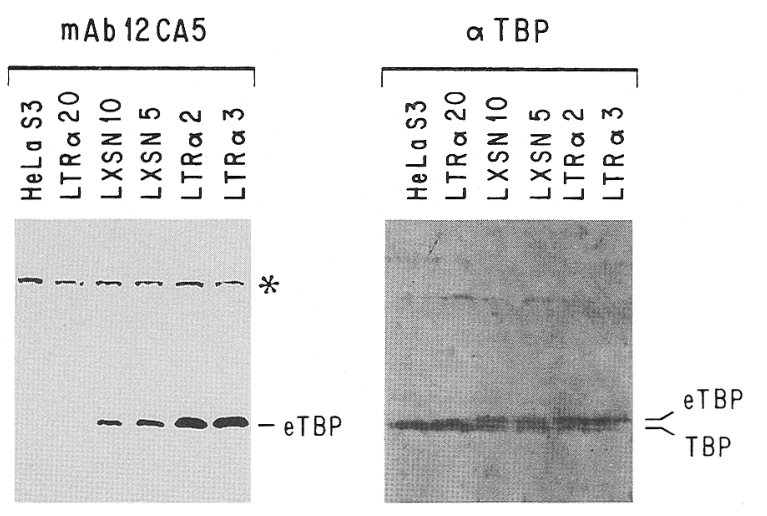

Figure 1. Autoregulation of TBP expression. (Left) Extracts of HeLa S3 cells and G418-resistant cell lines derived from HeLa S3 by infection with retrovirus vectors expressing epitopetagged TBP (LTReTBP or LXSNeTBP) were subjected to SDS-gel electrophoresis on a $10 \%$ polyacrylamide gel and subjected to Western blotting with mAb 12CA5. The position of eTBP is shown. An asterisk ( $\left.{ }^{*}\right)$ marks the position of a cross-reacting protein that is not observed in a nuclear extract. (Right) The same extracts were electrophoresed and subjected to Western blotting with a polyclonal rabbit antiserum raised against recombinant TBP (Lee et al. 1991). The positions of eTBP and wild-type TBP expressed from the endogenous human genes are shown. nizes both wild-type TBP and eTBP. The results (Fig. 1, right) show that cells expressing increasing levels of eTBP contain decreasing concentrations of the wild-type TBP expressed from the endogenous cellular gene. The total level of wild-type TBP plus eTBP was approximately constant between the different HeLa clones examined, suggesting that expression of the endogenous TBP gene is regulated so as to maintain a constant concentration of TBP. Further experiments were performed with clone LTR $\alpha 3$, in which $\sim 80 \%$ of total TBP is the epitope-tagged form.

\section{Purification of a TFIID complex with TATA box-binding activity}

Nuclear extract was prepared from $\alpha 3$ cells and fractionated by chromatography on phosphocellulose. Forty percent of the eTBP was eluted in the $0.5-1.0 \mathrm{M} \mathrm{KCl}$ fraction (D fraction), along with $7 \%$ of the nuclear protein and all of the TFIID activity. This fraction was then incubated with protein A-Sepaharose-linked mAb $12 \mathrm{CA} 5$ specific for the epitope tag. After extensive washing in high salt, the column was eluted with buffer containing the epitope peptide, and eluted fractions were analyzed by SDS-PAGE and silver staining (Fig. 2). Lane 3 shows the profile of polypeptides in the $\mathrm{D}$ fraction applied to the mAb $12 \mathrm{CA} 5$ column $10.5 \%$ of the $\mathrm{D}$ fraction used to purify the protein applied to lanes 5 and 6 ). Lane 7 shows the migration of eTBP expressed in Escherichia coli and purified using the mAb 12CA5 column and epitope peptide elution. Polypeptides purified from the $\alpha 3$ phosphocellulose $\mathrm{D}$ fraction in the first and second elutions with epitope peptide are shown in lanes 5 and 6 . These fractions contain eTBP and eight other major polypeptides with molecular weights from $\sim 250$ to $\sim 28 \mathrm{kD}$. None of these polypeptides was eluted from an mAb $12 \mathrm{CA} 5 \mathrm{col}-$ umn incubated with phosphocellulose $\mathrm{D}$ fraction from the parental HeLa cell line used to prepare $\alpha 3$ cells (lane 4 , which contains a staining artifact not seen in other analyses|. Consequently, this set of polypeptides is eluted from the mAb $12 \mathrm{CA} 5$ column because they are directly or indirectly associated with eTBP. Therefore, we refer to these polypeptides as TBP-associated factors or TAFs, as suggested by Dynlacht et al. (1991). We refer to the protein fraction shown in lanes 5 and 6 as the eTFIID complex. Purification of the eTFIID complex fraction is summarized in Table 1. Because they are metabolically labeled with ${ }^{32}$ P-labeled phosphate, the 250-, 78 -, and $50-\mathrm{kD}$ polypeptides of the eTFIID complex are phosphoproteins. eTBP also incorporates a low, but clearly detectable, level of ${ }^{32} \mathrm{P}$ (data not shown).

To analyze the number of TATA box-binding protein complexes in the eTFIID complex fraction, we performed electrophoretic mobility shift assays (EMSAs). The major DNA-protein complex formed on a 29-bp duplex DNA containing the adenvoirus 2 E1B TATA box did not enter a $4 \%$ polyacrylamide gel. Consequently, we analyzed the DNA-protein complex on a $1.4 \%$ agarose gel (Fig. 3). Purified eTFIID complex formed a single major complex with much lower mobility than the complex 


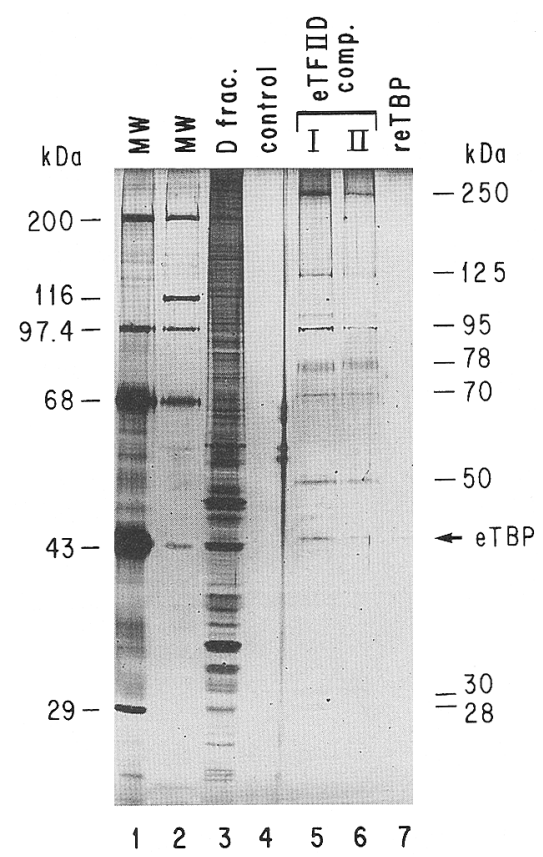

Figure 2. eTFIID complex purification. A silver-stained SDS$10 \%$ polyacrylamide gel is shown. (Lanes 1,2$)$ Molecular weight markers; (lane 3) $0.5 \%$ of the $\alpha 3$ cell phosphocellulose D fraction used in the purification of the eTFIID complex in lanes 5 and 6. The $\alpha 3$ cell $\mathrm{D}$ fraction was applied to an mAb 12CA5 column, and the column was washed and eluted with HAl peptide as described in Materials and methods. (Lane 5) The protein in the first elution with $\mathrm{HAl}$ peptide; (lane 6) the protein in the second elution with HAl peptide; (lane 4) a control fraction prepared in the same way as the sample in lane 5 , except that the $\mathrm{D}$ fraction applied to the mAb $12 \mathrm{CA} 5$ column was from HeLa S3 cells; (lane 7) eTBP partially purified from recombinant E. coli as described (Lee et al. 1991) and then applied to an $\mathrm{mAb}$ $12 \mathrm{CA} 5$ column and eluted with HAl peptide.

formed with recombinant human TBP (Fig. 3A), consistent with a higher molecular weight. The specificity of binding was similar for both complexes (Fig. 3B). Binding was competed by a 50 -fold excess of the unlabeled 29 -bp duplex containing the wild-type TATA box but not by an unrelated 30-bp duplex (ZRE) or a duplex with an identical sequence to the TATA box probe, except for a single substitution of a CG for a TA base pair at the third position of the TATA box. The DNA-protein complex formed by the eTFIID complex fraction contained TBP because anti-TBP immunoglobulin resulted in a supershift of the complex, whereas preimmune immunoglobulin did not (Fig. 3C).

\section{High recovery of activated transcriptional activity}

To quantitate recovery of transcriptional activity in the highly purified eTFIID complex fraction, we first assayed the amount of eTBP polypeptide in this fraction and in the phosphocellulose D fraction by Western blotting (Fig. 4B). The highly sensitive chemiluminescence technique used was quantitative but did not give a linear response. Twelve microliters of $D$ fraction resulted in a much darker signal than $6 \mu \mathrm{l}$, whereas $3 \mu \mathrm{l}$ of $\mathrm{D}$ fraction did not produce a detectable signal. Eleven microliters of the eTFIID complex fraction (lane 4) contained an amount of eTBP similar to $6 \mu \mathrm{l}$ of the phosphocellulose $\mathrm{D}$ fraction. Two microliters of a dilution of recombinant eTBP expressed in and purified from $E$. coli contained slightly less (but within twofold) eTBP than $11 \mu$ l of the eTFIID complex fraction. Activated transcription was then assayed in a reconstituted in vitro reaction using a template with a TATA box and five upstream binding sites for the yeast GAL4 protein $\left(\mathrm{pG}_{5} \mathrm{E} 4 \mathrm{~T}\right.$; Carey et al. 1990 ) and the GAL4-AH fusion protein (Giniger and Ptashne 1987), which has an acidic activation domain.

In the absence of any source of TFIID activity, no specific transcription could be detected in the in vitro transcription reaction (Fig. 4A, lane 1). A low level of specific transcription was detected when GAL4-AH was added (lane 2), probably because of a very low level of TFIID activity contaminating the partially purified general transcription factor fractions. Addition of $6 \mu$ l of phosphocellulose $D$ fraction resulted in a detectable level of basal transcription in the absence of added activator (lane 3). Addition of GAL4-AH stimulated transcription $>20$-fold (lane 4). Transcription reactions reconstituted with recombinant TBP showed much reduced activation by GAL4-AH (lanes 9-12). Significantly, transcriptional reactions reconstituted with $11 \mu$ of eTFIID complex resulted in levels of both basal (lane 5) and GAL4-AHactivated transcription (lane 6), very similar to those observed using the phosphocellulose D fraction. No activity was observed with a control fraction (lanes 7,8 ) prepared in parallel from the parental HeLa cells used to generate $\alpha 3$ cells (as in Fig. 2, lane 4). On a per TBP molecule basis, therefore, recovery of basal and activated TFIID transcriptional activity was close to $100 \%$ when

Table 1. Purification of eTFIID complex

\begin{tabular}{lcccc}
\hline & Protein $(\mathrm{mg})$ & Western eTBP units & Specific activity (U/mg protein) & Fold purification \\
\hline NE & 2200 & 29,000 & 13 & 1 \\
D fraction & 142 & 12,000 & 85 & 6.5 \\
eTFIID & 0.01 & 1,900 & 190,000 & 15,000 \\
\hline
\end{tabular}

Total protein in the nuclear extract and phosphocellulose $\mathrm{D}$ fraction was determined by the method of Bradford. Total protein in the eTFIID complex fraction was estimated by analyzing an aliquot by SDS-gel electrophoresis, followed by silver staining and comparison to a dilution series of BSA on the same gel. Western eTBP units were determined from Western blot dilution series as in Fig. $2 B$. 
A

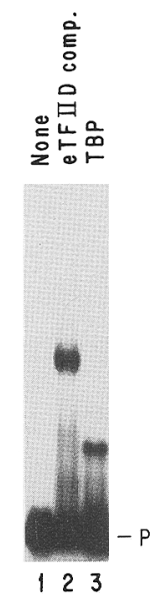

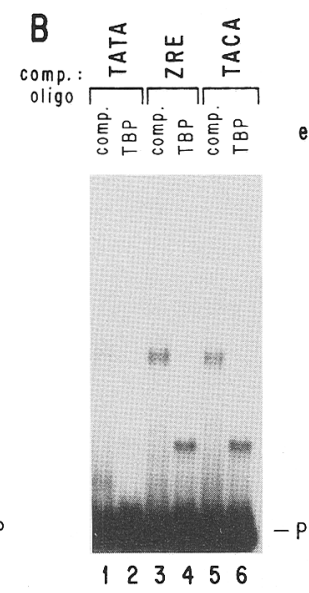

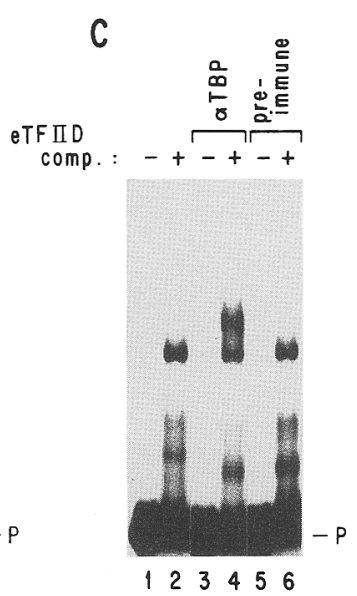

Figure 3. EMSAs of eTFIID complex and recombinant TBP. $(A)$ Assays were performed as described in Materials and methods and subjected to electrophoresis in a $1.4 \%$ agarose gel. $(B)$ Competitions were performed with a 50 -fold molar excess of the indicated competitors over the labeled E1B TATA box probe. Lanes marked comp. contained the eTFIID complex fraction. Lanes marked TBP contained recombinant TBP. (C) DNA-protein complexes formed with the eTFIID complex fraction were untreated (lane 2), treated with IgG purified from anti-TBP rabbit serum (lane 4), or treated with IgG purified from the preimmune serum (lane 6) before electrophoresis. Probe was untreated (lane 1) or treated with anti-TBP IgG (lane 3) or preimmune TBP (lane 5) to demonstrate that the IgG preparation did not produce detectable retarded complexes.

comparing the highly purified eTFIID complex and the phosphocellulose $\mathrm{D}$ fraction, the earliest fraction in TFIID purification in which transcriptional activity can be assayed.

The eTFIID complex mediates activation by diffent classes of activators and from a promoter lacking a TATA box

To determine whether the eTFIID complex could mediate activation of transcription by diverse classes of activators, we performed reconstituted in vitro transcription reactions with the $Z$ ta activator of Epstein-Barr virus and a derivative of the adenovirus 2 ElA protein. $\mathrm{Zta}$ is in the bZip class of transcription factors (Farrell et al. 1989; Chang et al. 1990; Flemington and Speck 1990; Lieberman and Berk 1990|. The Zta amino-terminal activation domain is neither acidic nor significantly enriched in any one type of amino acid residue (Giot et al. 1991; Lieberman and Berk 1991). With a template containing a TATA box and seven upstream Zta-binding sites, purified Zta stimulated transcription $\sim 10$-fold in reactions reconstituted with either phosphocellulose $D$ fraction or eTFID complex (Fig. 5A).

To analyze activation of transcription in vitro by the E1A activation domain, we expressed in and purified from $E$. coli a GAL4-E1A fusion protein that is highly active in vivo (Lillie and Green 1989). This GAL4-E1A fusion protein stimulates transcription $\sim 10$-fold with the $\mathrm{pG}_{5} \mathrm{E} 4 \mathrm{~T}$ template, whereas a double point mutant $(\mathrm{A} 174, \mathrm{~A} 177)$ with greatly reduced in vivo function (Martin et al. 1990) is greatly reduced for in vitro activation (T.G. Boyer and A.J. Berk, unpubl.). Although the 49residue E1A activation domain is overall somewhat acidic, acidic residues do not contribute greatly to activation functions (Martin et al. 1990; Webster and Ricciardi 1991). As for GAL4-AH and Zta, GAL4-E1A activated transcription to a comparable extent with both the phosphocellulose $\mathrm{D}$ fraction and the eTFIID complex (Fig. 5B).

A component of the TFIID fraction is also required for in vitro transcription from a template lacking a TATA box but containing the initiator promoter element of the
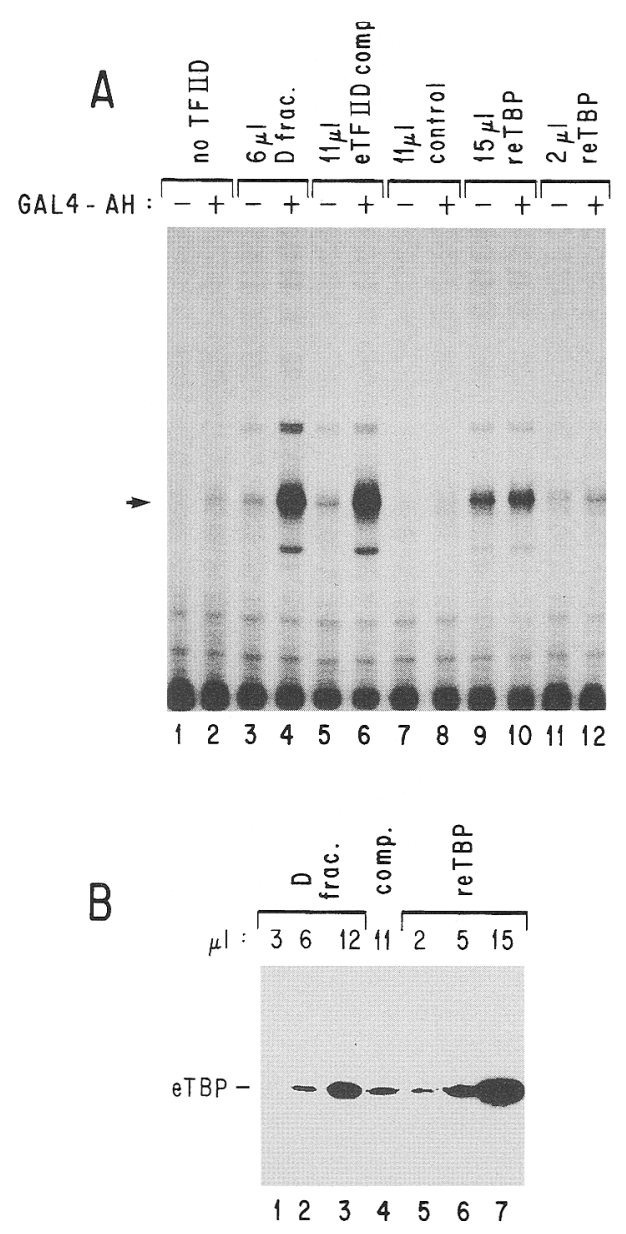

Figure 4. Recovery of TFIID activity for GAL4-AH-stimulated transcription. $(A)$ Primer extension assays of reconstituted in vitro transcription. Reactions were performed as described in Materials and methods in the absence $(-)$ or presence $(+)$ of GAL4-AH with the indicated sources of TFIID activity. $(\rightarrow)$ The position of the major specific transcripts. The control fraction (lanes 7,8 ) was prepared as for Fig. 2, lane $4 .(B)$ Quantitative Western blotting of eTBP using $\mathrm{mAb} 12 \mathrm{CA}$. The indicated microliters of D fraction from $\alpha 3$ cells, eTFIID complex fraction prepared from it, and a dilution of recombinant eTBP isolated from engineered $E$. coli were subjected to electrophoresis and Western blotting. 


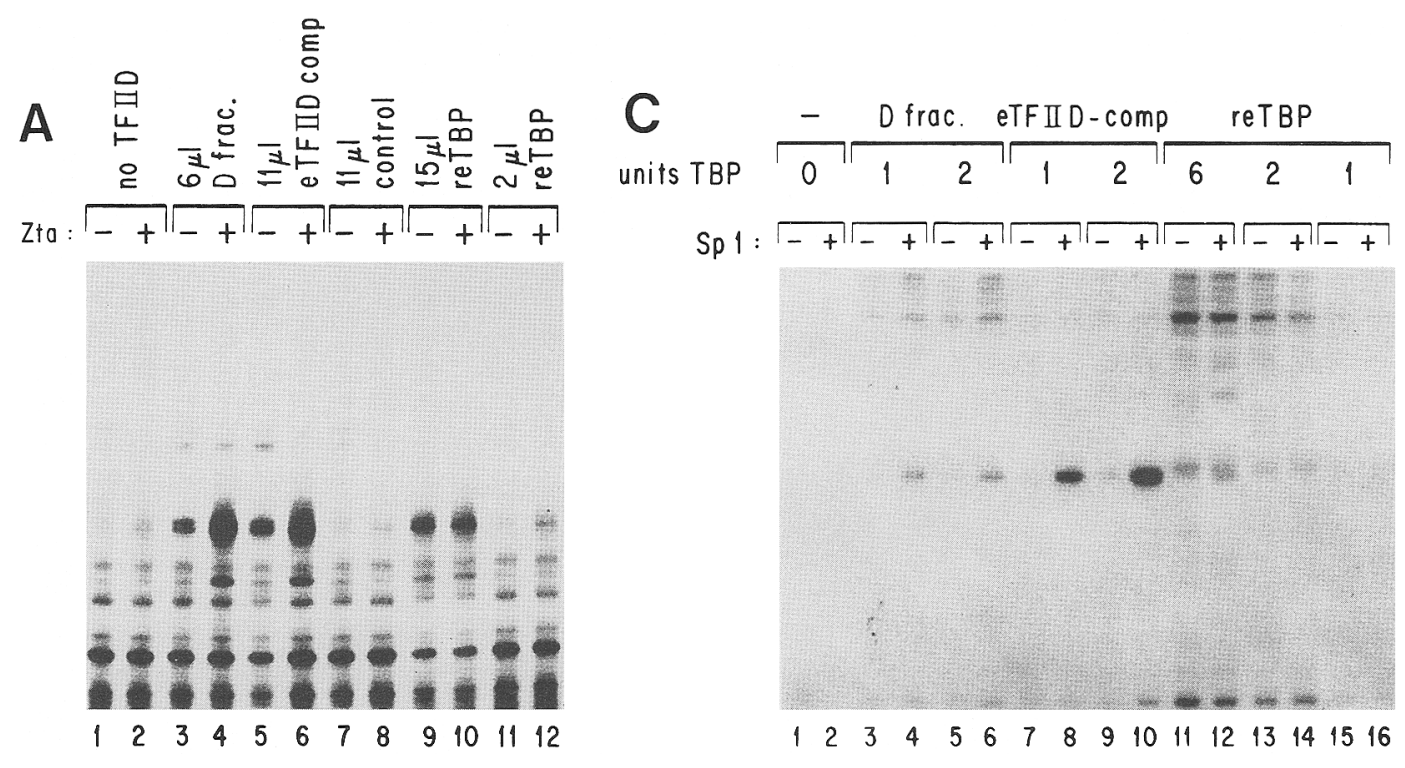

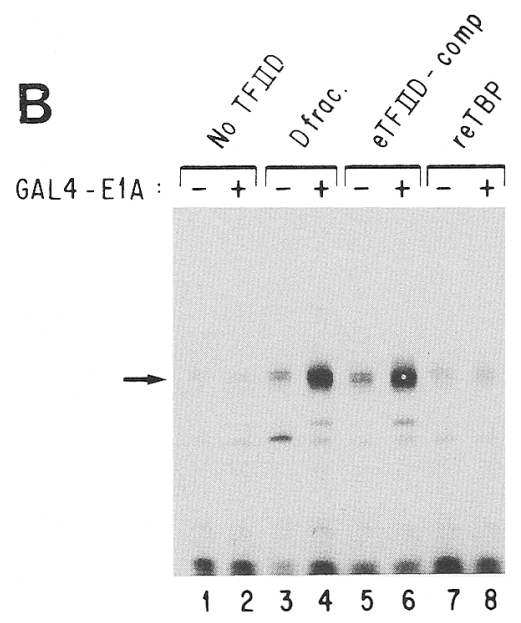

Figure 5. Recovery of TFIID activity for stimulation of transcription by different activator proteins. $(A)$ Reconstituted in vitro transcriptional reactions were performed as for Fig. 4A, with $\mathrm{Zta}$ added as indicated. $(B)$ Reconstituted in vitro transcriptional reactions were performed as for Fig. 4A with the indicated sources of TFIID activity. GAL4-E1A was added as indicated $(+1$. The concentrations of eTBP in these preparations of $D$ fraction, eTFIID complex, and recombinant eTBP were determined by quantitative Western blotting as shown in Fig. 4B. Equivalent amounts of eTBP were added in lanes 3-8. (C) The template used in these reconstituted in vitro transcriptional reactions (plasmid VI, Smale et al. 1990) contains the SV40 21-bp repeat region 42 bp upstream of the terminal transferase gene initiator element (Smale and Baltimore 1989). The sources of TFID activity are indicated. The concentration of eTBP in these preparations was determined by quantitative Western blotting. Equivalent concentrations of eTBP in these protein fractions were added to the reactions in lanes $3,4,7,8,15$, and 16 . Twice as much eTBP in these protein fractions was added to the reactions in lanes 5,6,9,10,13, and 14. Six times this amount of recombinant eTBP prepared from engineered $E$. coli was added to the reaction in lanes 11 and $12 . \mathrm{Sp} 1$ purified by three cycles of affinity chromatography was added to the transcriptional reactions as indicated $(+1$.

terminal transferase gene (Smale et al. 1990; Pugh and Tiian 1991, 1992). The eTFIID complex fraction also supported Spl (Kadonaga et al. 1987)-activated transcription from this promoter (Fig. 5C). The level of transcription was higher on a per TBP molecule basis than observed for the phosphocellulose $\mathrm{D}$ fraction, probably because the $\mathrm{D}$ fraction contains inhibitors of transcription from this template. Transcription with recombinant TBP showed much reduced activation by $\mathrm{Spl}$ over a broad range of TBP concentrations. At high concentrations of recombinant TBP there was heterogeneity in the sites of transcription initiation, possibly resulting from the binding of TBP to low-affinity sites on the template DNA. Spl also stimulated transcription from a TATA box-containing promoter in reactions reconstituted with the eTFIID complex fraction (data not shown). These results demonstrate that the eTFIID complex contains all the activities of the D fraction required for stimulation of transcription by the four distinct types of activation domains present in GAL4-AH, Zta, E1A, and Spl, as well as for transcription from the terminal transferase initiator in the absence of a TATA box.

\section{The eTFIID complex produces an extended footprint over the adenovirus major late promoter}

TFIID partially purified from HeLa cells produced an extended footprint on the adenovirus major late promoter (Sawadogo and Roeder 1985; Nakajima et al. 1988) compared with the footprint produced by the recombinant human TBP (Hoffman et al. 1990; Kao et al. 1990; Peterson et al. 1990). However, because the partially purified TFIID fraction used contained a large number of polypeptides, it was not clear whether this extended footprint was the result of TFIID binding or the binding of other proteins in the partially purified fraction. We reexamined this question using the highly purified eTFIID complex fraction. As observed earlier for recombinant TBP, recombinant eTBP generated an $\sim 20$-bp footprint centered over the TATA box (Fig. 6, lanes 6,7). In con- 


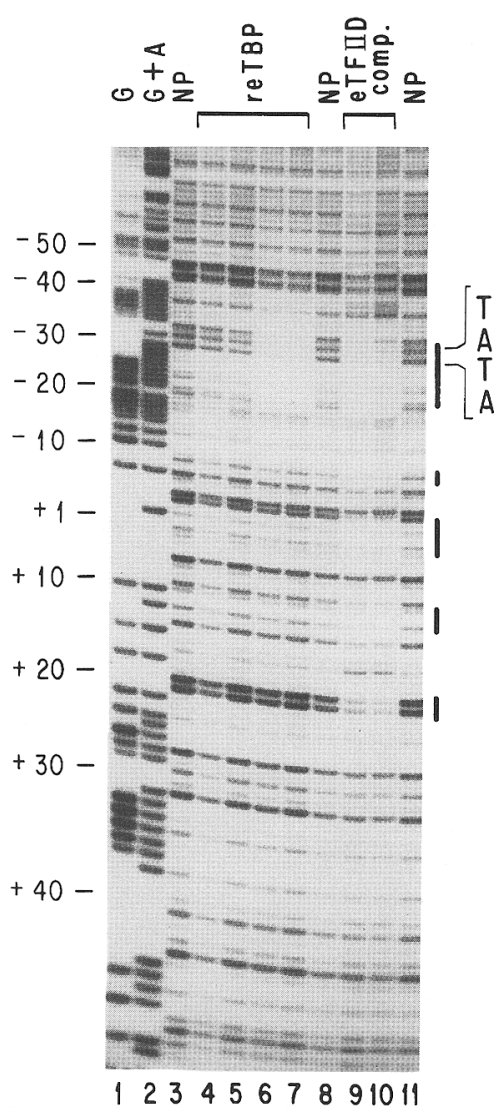

Figure 6. DNase I footprinting activity on the adenovirus 2 major late promoter. Positions along the major late promoter sequence are indicated to the left of the G and G + A MaxamGilbert sequencing ladders (lanes 1,2). DNase I digestion patterns in the absence of other added proteins are in lanes 3,8 , and 11. Increasing amounts of recombinant eTBP prepared from engineered $E$. coli were present in the reactions in lanes $4-7$. The eTFIID complex fraction prepared as in Fig. 2, lane 5, was added to the reactions analyzed in lanes 9 and 10 . The position of the TATA sequence is shown at right. Regions clearly protected from DNase I digestion by the eTFIID complex fraction are shown by vertical lines at right.

trast, the footprint generated by the eTFIID complex fraction extended from the same $5^{\prime}$ border as the eTBP footprint to a region extending over and beyond the site of initiation (lanes 9,10). Clear protections were observed at $-8,-2$ to $+4,+10$ to +13 , and +22 to +23 on the noncoding strand. In contrast to this extended footprint on the adenovirus 2 major late promoter, the DNase I footprint produced by the eTFIID complex fraction on the adenovirus 2 E4 promoter, which does not have a strong initiator region, was similar to the $\sim 20$-bp footprint centered over the TATA box produced by recombinant TBP (data not shown). These results suggest that one or more of the polypeptides of the eTFIID complex other than TBP makes specific contacts with the initiator region of the major late promoter.

\section{Polypeptides associated with the 17S TFIID complex}

We subjected the eTFIID complex to sedimentation ve- locity centrifugation (Fig. 7) to compare it with earlier results on the sedimentation of TFIID activity. The 250-, $125-, 95-, 78-$, and $50-\mathrm{kD}$ polypeptides clearly cosedimented, peaking in fraction 4 . This corresponds to a sedimentation coefficient of $17 \mathrm{~S}$, in perfect agreement with the value obtained by Samuels et al. (1982) and Conoway et al. (1991). In contrast, the $70-\mathrm{kD}$ polypeptide in the eTFIID complex fraction (Fig. 2) sedimented as a distinct molecular species of $\sim 4 \mathrm{~S}$.

The eTBP polypeptide was detectable by silver staining on the original stained gel where it was observed to cosediment with the higher molecular weight polypeptides at $17 \mathrm{~S}$, but it does not appear clearly in this reproduction (Fig. 7A). It was detected readily by Western blotting (Fig. 7B) of fractions from a sucrose gradient of phosphocellulose $\mathrm{D}$ fraction run in parallel to the gradient analyzed in Figure 7A. The majority of eTBP sedimented at $17 \mathrm{~S}$, whereas two minor complexes sedimented at $\sim 7 \mathrm{~S}$ and $\sim 4 \mathrm{~S}$. On the basis of these results and the previous reports that TFIID activity sediments at $17 \mathrm{~S}$ (Samuels et al. 1982; Conoway et al. 1991), we conclude that the major TFID complex contains the 250-, 125-, 95-, 78-, and $50-\mathrm{kD}$ polypeptides as well as TBP ( $38 \mathrm{kD})$. We could not distinguish whether or not the smaller polypeptides of 30 and $28 \mathrm{kD}$ in the eTFIID complex fraction were present in this multisubunit $17 \mathrm{~S}$ protein. The eTBP sedimenting at $\sim 7 \mathrm{~S}$ may be associated with the RNA polymerase I transcription factor SL1, which should have been present in the phosphocellulose $D$ fraction (Comai et al. 1992). This and the more slowly sedimenting $4 \mathrm{~S}$ form of eTBP have not been characterized further.

\section{Discussion}

These results are consistent with the model that a single major TFIID complex functions in transcription by RNA polymerase II in human cells. This conclusion rests on the extensive purification of the eTFIID complex fraction (Fig. 2) and the observation that this purified protein fraction forms a single TATA box-binding macromolecular complex visualized by EMSA (Fig. 3). The eTFIID complex fraction contained all of the activities in the phosphocellulose $\mathrm{D}$ fraction required for the stimulation of transcription by the four different types of activator proteins tested, GAL4-AH, Zta, GAL4-E1A, and Sp1 (Figs. 4 and 5). It also supported transcription from a promoter lacking a TATA box (Fig. 5C). Therefore, rather than there being a diverse set of TFIID complexes composed of TBP in association with different combinations of TAFs, as recently postulated (Pugh and Tjian 1992; Sharp 1992), our results suggest that a single major holoTFIID supports activation by diverse classes of activation domains.

The structure of holo-TFID and its interaction with the adenovirus 2 major late promoter, as presently understood, is diagramed in Figure 8. TAFs clearly established to be subunits of holo-TFIID are indicated. TBP is known to interact directly with the TATA box, but the positions of the TAFs relative to TBP, to each other, and 


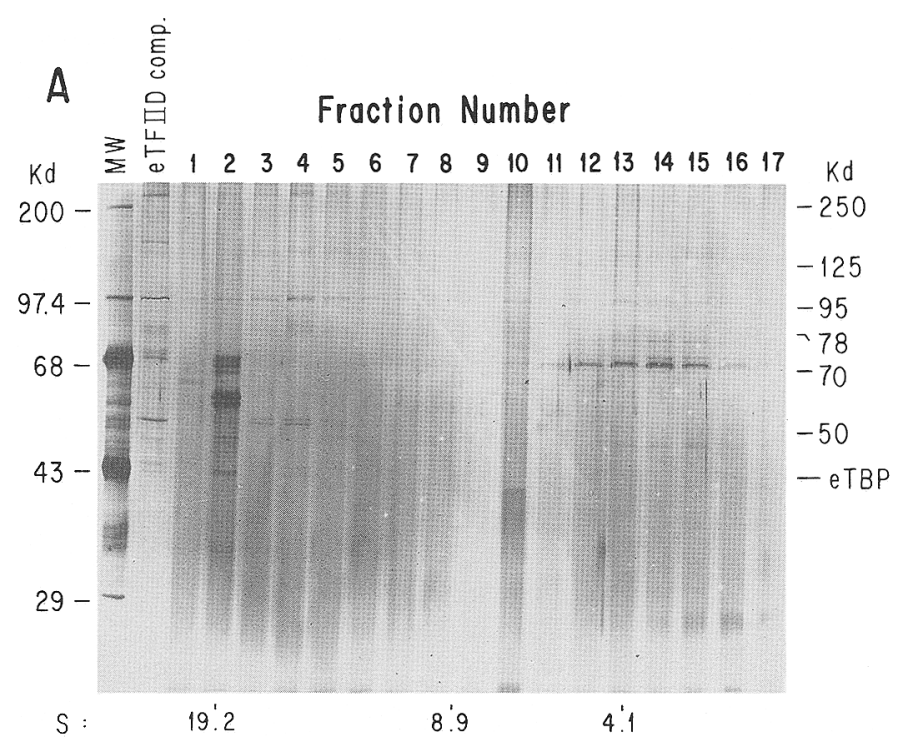

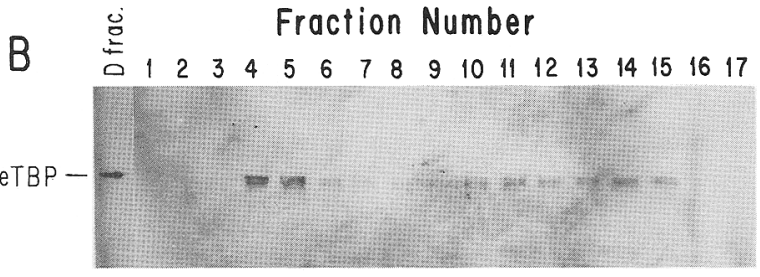

Figure 7. Sedimentation velocity centrifugation of the eTFIID complex fraction. (A) Silver-stained gel of fractions from a sucrose gradient of an eTFIID complex preparation. The gradient was centrifuged as described in Materials and methods. The peak positions of marker proteins centrifuged in a parallel gradient during the same centrifugation are shown at the bottom in terms of Svedberg units. The eTFIID complex fraction layered on the gradient is shown in lane 2, and marker proteins are shown in lane 1 . The major bands between $\sim 55$ and $\sim 65 \mathrm{kD}$ in fraction 2 are artifacts of this particular fraction resulting from contaminating protein in this sample. $(B)$ Western blot of fractions from a sucrose gradient of $D$ fraction prepared from $\alpha 3$ cells performed with mAb 12CA5. Centrifugation was as for the gradient in $A$. to the DNA are not established. The diagram emphasizes that one or more of the TAFs interacts closely with the initiator sequence element at the transcription start site. We postulate that this is the case because the TFIID complex produces an extended footprint on the major late promoter, which has an initiator sequence (Fig. 6), but not on the adenovirus E4 promoter, which does not have an initiator sequence. The TFIID complex is shown extending along the DNA from the TATA box bound by TBP to a region beyond the transcription start site, in accordance with the DNase I footprinting data of Sawadogo and Roeder (1985) and Figure 6. The surface of TBP facing upstream is shown exposed, consistent with the result that the upstream border of the footprint is similar for both the TFIID complex and isolated TBP (Fig. 6).

Much remains to be learned about how different activation domains interact with this holo-TFIID complex to stimulate transcription. It is known that the activation domains of herpes simplex virus VP16 (Stringer et al. 1990; Ingles et al. 1991), E1 A (Horikoshi et al. 1991; Lee et al. 1991), and Zta (Lieberman et al. 1991) interact directly with isolated TBP. Therefore, it is significant that the upstream border of the holo-TFIID footprint is similar to that of isolated TBP (Fig. 6). This indicates that the upstream surface of the TBP subunit in holo-TFIID would be accessible for interactions with these and other regulatory transcription factors. Activation domains also may have additional interactions with TAFs and other general transcription factors (e.g., Lin and Green 1991). Minor alternative forms of TFIID with alternative or additional TAFs might be required for activation by some types of activators. It should also be kept in mind that the TFIIA/J and RNA polymerase II TFIIE/F/H fractions used in these in vitro transcription reactions were only partially purified. Consequently, proteins in these preparations, in addition to the general transcription factors, could contribute to the stimulation of transcription by the activator proteins analyzed. However, all of the required proteins in the phosphocellulose $\mathrm{D}$ fraction were present in the highly purified eTFIID complex fraction.

It has been suggested that transcriptional activation might operate in part through inhibitors of initiation and relief of this inhibition by activator proteins (Meisterenst et al. 1991; Meisterenst and Roeder 1991). Although these studies have demonstrated the existence of such inhibitory factors, our results show that the TAFs associated with the holo-TFIID isolated here do not inhibit the basal activity of TBP. On a per TBP molecule basis, the activity of the eTFIID complex was no lower in the absence of activator than the activity of eTBP purified from $E$. coli (e.g., Fig. 4A, cf. lanes 5 and 11).

The expression of eTBP from the retroviral long ter-

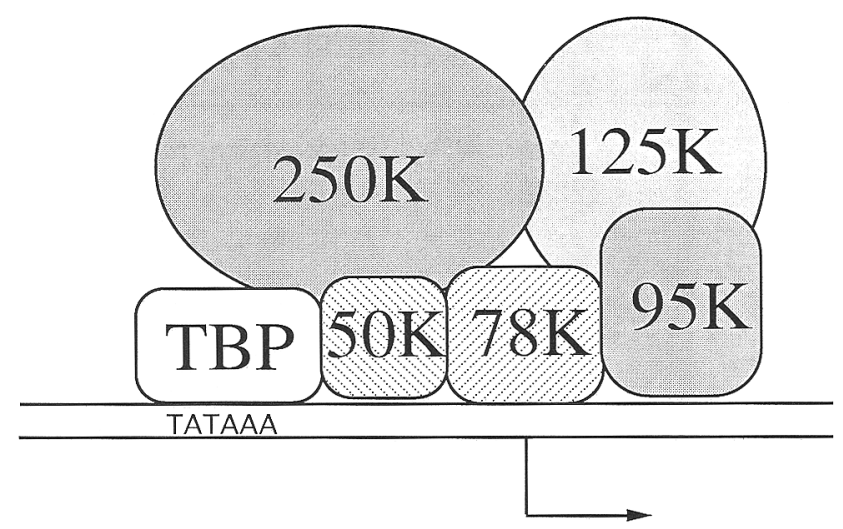

Figure 8. Diagram of holo-TFIID bound to the adenovirus 2 major late promoter. TAFs clearly established to be subunits of holo-TFIID are diagramed. TBP is known to bind to the TATA box, but the relative positions of the TAFs to TBP, to each other, and to the DNA are hypothetical (for further explanation of the model, see Discussion). 
minal repeat (LTR) present in the vectors used to transform HeLa cells resulted in a decrease in the concentration of endogenous wild-type TBP. The total concentration of eTBP plus TBP remained approximately constant in the different transformed cell lines analyzed (Fig. 1). These results indicate that expression of the endogenous TBP is regulated so as to maintain TBP at a constant concentration. This finding raises the possibility that TBP may autoregulate transcription from its own promoter in a manner analogous to the autoregulation of bacteriophage $\lambda$ repressor (Ptashne 1986). Further studies will be needed to determine the mechanism regulating the expression of endogenous TBP in these cells. The $\alpha 3$ cells and the method of TFIID complex purification described here should be useful in further studies of transcriptional initiation by RNA polymerase II and its control by regulatory transcription factors.

\section{Materials and methods \\ Construction of plasmids}

The human TBP cDNA in clone pKB104 (Kao et al. 1990) was polymerase chain reaction (PCR) amplified using an oligonucleotide primer for the amino terminus of the gene, which introduced the amino acid sequence MGYPYDVPDYAV immediately amino-terminal to the second codon (GAT) of TBP. An EcoRI site was also introduced at both the $5^{\prime}$ and $3^{\prime}$ ends of the protein-coding region during the PCR reaction. The amplified DNA fragment was inserted into the unique EcoRI site of the pSR $\alpha$ MSVtkneo retroviral expression vector (Muller et al. 1991) or the pLXSN retroviral expression vector (Miller and Rosman 1989) to create pLTReTBP and PLXSNeTBP, respectively.

\section{Establishment of cell lines expressing eTBP}

Helper-free retroviral stocks were prepared by transient expression in COS cells. Retroviral expression plasmid pLTReTBP or pLXSNeTBP was cotransfected with pSV- $\Psi^{-}-\mathrm{A}-\mathrm{MLV}$, which contains $\Psi^{-}$proviral sequences expressing an amphotropic coat protein cloned into a SV40-based expression vector (N.R. Landau and D.R. Littman, unpubl.). Transfections were performed using the calcium phosphate method (Graham and van der Eb 1973) on $2 \times 10^{6} \mathrm{COS}$ cells/100-mm plate. Medium containing virus was harvested at $48 \mathrm{hr}$ post-transfection. Freshly seeded HeLa S3 cells $\left(2 \times 10^{6}\right.$ cells at $6 \mathrm{hr}$ postseeding in a $10-\mathrm{cm}$ plate) were infected for $3 \mathrm{hr}$ with $4 \mathrm{ml}$ of virus stock containing $8 \mu \mathrm{g} / \mathrm{ml}$ of Polybrene. The medium was then replaced with $10 \mathrm{ml}$ of fresh DMEM supplemented with $5 \%$ fetal calf serum and $8 \mu \mathrm{g} / \mathrm{ml}$ of Polybrene. At 2 days postinfection, cells were plated at $1: 10,1: 100$, and $1: 200$ dilutions into Dulbecco's modified Eagle medium (DMEM) supplemented with $5 \%$ fetal calf serum plus $1.0 \mathrm{mg} / \mathrm{ml}$ of G418. After $\sim 2$ weeks, G418-resistant colonies were isolated in cloning cylinders and expandeu into individual cell lines. Expression of eTBP protein in 35 cell lines was examined by Western analysis with $\mathrm{mAb}$ 12CA5. Cell lines expressing еTBP were maintained in $500-\mathrm{ml}$ suspension cultures of S-MEM plus $5 \%$ calf serum and $200 \mu \mathrm{g} / \mathrm{ml}$ of G418. Cells were expanded into larger volumes in media without G418.

\section{Affinity purification of eTFIID complex}

mAb 12CA5 was directly coupled to protein A-Sepharose (Pharmacia) with dimethylpimelimidate, as described (Harlow and
Lane 1988). One milliliter of the $1.0 \mathrm{M} \mathrm{KCl}$ phosphocellulose fraction $(1.5 \mathrm{mg} / \mathrm{ml}$ of undialyzed fraction $\mathrm{D}$; Dignam et al. 1983) of the LTR $\alpha 3$ nuclear extract containing the eTFIID complex was incubated with $0.2 \mathrm{ml}$ of coupled protein $\mathrm{A}-\mathrm{mAb}$ $12 \mathrm{CA} 5$ affinity resin in $0.7 \mathrm{M} \mathrm{KCl} \mathrm{D}$ buffer $[0.7 \mathrm{M} \mathrm{KCl}, 20 \mathrm{mM}$ HEPES (pH 7.9), 20\% glycerol, $0.2 \mathrm{~mm}$ EDTA, $0.5 \mathrm{~mm}$ DTT, 0.5 mM PMSF, $0.1 \%$ NP-40], with rotation at $4^{\circ} \mathrm{C}$ for $8 \mathrm{hr}$. The protein A-Sepharose beads were centrifuged in a microcentrifuge at $6000 \mathrm{rpm}$ and $4^{\circ} \mathrm{C}$ and washed three times with $0.4 \mathrm{M}$ $\mathrm{KCl} \mathrm{D}$ buffer plus $0.1 \% \mathrm{NP}-40$ and twice with $0.1 \mathrm{M} \mathrm{KCl} \mathrm{D}$ buffer. To elute the eTFIID complex from the affinity resin, 100 $\mu \mathrm{l}$ of the elution buffer containing the flu epitope oligopeptide (Field et al. 1988; TyrProTyrAspValProAspTyrAla, UCLA Peptide Synthesis Facility) at $1 \mathrm{mg} / \mathrm{ml}$ in $0.1 \mathrm{M} \mathrm{KCl} \mathrm{D}$ buffer was added to the semiwet beads and incubated for $30 \mathrm{~min}$ at room temperature. In some cases, the elution step was repeated once. Preparation of the partially purified epitope-tagged TBP protein from E. coli was as described previously (Lee et al. 1991) and then affinity purified as described above. As a control, the $1.0 \mathrm{M}$ $\mathrm{KCl}$ phosphocellulose $\mathrm{D}$ fraction $(1.5 \mathrm{mg} / \mathrm{ml})$ of nuclear extract from the parental HeLa S3 cells was subjected to the same procedure.

In vivo labeling and preparation of LTR $\alpha 3$ nuclear extract

Monolayer LTR $\alpha 3$ cells or HeLa S3 cells on $150-\mathrm{mm}$ plates at $80 \%$ confluency were washed twice with Tris-buffered saline. For ${ }^{35} \mathrm{~S}$-labeling, cells were washed with low methionine-labeling medium (GIBCO) and $1.2 \mathrm{mCi}$ of Trans ${ }^{35} \mathrm{~S}$-label (ICN) was added to $4 \mathrm{ml}$ of low methionine-labeling medium supplemented with $2 \%$ dialyzed newborn calf serum per $150-\mathrm{mm}$ plate. For ${ }^{32} \mathrm{P}$-labeling, cells were washed with phosphate-free DMEM twice, and $5 \mathrm{mCi}$ of $\mathrm{H}_{3}{ }^{32} \mathrm{PO}_{4}$ (ICN) was added to $4 \mathrm{ml}$ of phosphate-free DMEM supplemented with $2 \%$ dialyzed newborn calf serum per $150-\mathrm{mm}$ plate. Labeling was for $5 \mathrm{hr}$, after which cells were removed from the plate with trypsin-EDTA and washed with Tris-buffered saline. Nuclear extracts were made from the labeled cells following a small-scale procedure (Lee et al. 1988). Immunoaffinity purification of the labeled eTFIID complex from $100 \mu \mathrm{l}(20 \mu \mathrm{g})$ of the $1.0 \mathrm{M} \mathrm{KCl}$ phosphocellulose D fraction of the LTR $\alpha 3$ nuclear extract was performed essentially as described above. To immunoprecipitate the labeled TFIID complex from the $1.0 \mathrm{M} \mathrm{KCl}$ phosphocellulose $D$ fraction of the HeLa S3 nuclear extract, $100 \mu l(20 \mu \mathrm{g})$ of the HeLa S3 phosphocellulose D was incubated with $5 \mu$ l of antihuman TBP rabbit antiserum or preimmune serum for $3 \mathrm{hr}$ at $4^{\circ} \mathrm{C}$. The immune complex was precipitated with protein A-Sepharose (Pharmacia) after a 2-hr incubation at $4^{\circ} \mathrm{C}$. Pellets were washed similarly as in the process of affinity purification of eTFIID complex and then resuspended in $1 \times$ Laemmli sample buffer.

\section{Expression and purification of GAL4-E1A}

DNA sequences encoding amino acids 1-147 of GAL4 fused in-frame to DNA sequences encoding amino acids 121-223 of the adenovirus large E1A protein were excised from pTM1GAL4-E1A (Lee et al. 1991) and inserted into the NcoI and BamHI sites of $\mathrm{pET}$ C (Novagen). GAL4-E1A fusion protein was expressed in E. coli strain BL21. One-liter cultures were grown at $37^{\circ} \mathrm{C}$ to an $\mathrm{OD}_{600}$ of $0.35-0.40$, and IPTG was added to a final concentration of $0.4 \mathrm{~mm}$. After $1 \mathrm{hr}$ at $30^{\circ} \mathrm{C}$, the cells were collected by centrifugation, washed once in GET buffer $(50$ $\mathrm{mm}$ glucose, $25 \mathrm{~mm}$ Tris- $\mathrm{HCl}$ at $\mathrm{pH} 7.9,10 \mathrm{~mm}$ EDTA), and resuspended in GET plus lysozyme at a final concentration of 4 $\mathrm{mg} / \mathrm{ml}$. After $20 \mathrm{~min}$ on ice, the cells were pelleted at $7700 \mathrm{~g}$ for 
$10 \mathrm{~min}$ (Sorvall SS-34 rotor). The cell pellet was resuspended in $10 \mathrm{ml}$ of TE buffer $10 \mathrm{~mm}$ Tris- $\mathrm{HCl}$ at $\mathrm{pH} 7.4,1 \mathrm{~mm}$ EDTA, 1 mM PMSF, $1 \mathrm{~mm}$ DTT/ plus $10 \mu \mathrm{M} \mathrm{ZnCl}_{2}$. Cells were then quick frozen in liquid nitrogen and thawed one time before the addition of $20 \mathrm{ml}$ of $0.1 \mathrm{M} \mathrm{KCl} \mathrm{D}$ buffer $[0.1 \mathrm{M} \mathrm{KCl}, 20 \mathrm{mM}$ HEPES (pH 7.9), 20\% glycerol, $0.2 \mathrm{~mm}$ EDTA, $0.5 \mathrm{~mm}$ DTT, $0.5 \mathrm{~mm}$ PMSF] plus $10 \mu \mathrm{MnCl}_{2}$. NP-40 was added to a final concentration of $0.05 \%$, and the suspension was sonicated on ice. Insoluble material was removed by centrifugation for $20 \mathrm{~min}$ at $17,000 \mathrm{~g}$ (Sorvall SS-34 rotor). Solid ammonium sulfate was added to the supernatant to a final concentration of $15 \%$ over a period of $60 \mathrm{~min}$ at $4^{\circ} \mathrm{C}$. The precipitated proteins were collected by centrifugation at $12,000 \mathrm{~g}$ for $15 \mathrm{~min}$ at $4^{\circ} \mathrm{C}$, and the resultant supernatant was brought to $40 \%$ of saturation in ammonium sulfate as before. After centrifugation, as before, the precipitated proteins were resuspended in $0.1 \mathrm{M} \mathrm{KCl} \mathrm{D}$ buffer plus $10 \mu \mathrm{M} \mathrm{ZnCl} 2$ and dialyzed against 300 volumes of the same buffer for $3 \mathrm{hr}$ at $4^{\circ} \mathrm{C}$. The dialysate was applied directly to a 2-ml S-Sepharose Fast Flow column equilibrated previously with $0.1 \mathrm{M} \mathrm{KCl} \mathrm{D}$ buffer plus $10 \mu \mathrm{M} \mathrm{ZnCl}_{2}$. The column was washed with three column volumes of the same buffer, and proteins retained on the column were then eluted by a step gradient of 0.2 and $0.3 \mathrm{M} \mathrm{KCl} \mathrm{D}$ buffer plus $10 \mu \mathrm{M} \mathrm{ZnCl}$. GAL4E1A protein eluted in the $0.3 \mathrm{M} \mathrm{KCl}$ step fraction. Peak protein fractions were pooled, dialyzed against $0.1 \mathrm{M} \mathrm{KCl} \mathrm{D} \mathrm{buffer} \mathrm{plus}$ $10 \mu \mathrm{M} \mathrm{ZnCl}_{2}$, and stored at $-70^{\circ} \mathrm{C}$. GAL4-E1A proteins were $\sim 70 \%$ pure at this stage, as judged by SDS-PAGE followed by Coomasie blue staining.

\section{Transcription assays}

Transcriptional activities of the affinity-purified eTFIID complex and recombinant eTBP protein were assayed by in vitro transcription, followed by primer extension as described (Schmidt et al. 1989). To study transcriptional activation by GAL4-AH and GAL4-E1A fusion protein, $100 \mathrm{ng}$ of plasmid template pG5E4T (Carey et al. 1990) containing five GAL4binding sites upstream of the adenovirus E4 TATA box was used. Expression and purification of GAL4-AH from E. coli were as described (Carey et al. 1990). For studying transcriptional activation by $\mathrm{Zta}$ activator, $100 \mathrm{ng}$ of plasmid $\mathrm{pZ}, \mathrm{E} 4 \mathrm{~T}$ (M. Carey, unpubl.) containing seven Zta-binding sites upstream of the E4 TATA box was utilized. Expression and purification of $\mathrm{Zta}$ activator were as described (Lieberman and Berk 1991). To study transcriptional activation by Spl protein on a TATA boxminus promoter, $100 \mathrm{ng}$ of plasmid VI containing the SV40 21bp repeats and the initiator promoter element of the terminal transferase gene, but lacking the TATA box (Smale et al. 1990), was included in the reaction. Sp1 was purified from HeLa cell nuclear extracts by chromatography on Sephacryl S-300, followed by three successive passes over an oligonucleotide affinity column (Kadonaga and Tjian 1986). Partially purified TFIIA/ J, TFIIE/F/H/RNA polymerase II, and recombinant TFIIB were used to reconstitute transcription. Purification of the basic transcription factors into a fraction of TFIIA and $J$ and a fraction containing RNA polymerase II, TFIIE, F, and $\mathrm{H}$ (polymerase II, $\mathrm{E} / \mathrm{F}$ fractions| from a HeLa cell nuclear extract was essentially as described (Lin and Green 1991). The TFIIA fraction also contains TFIIJ (Cortes et al. 1992). The polymerase II, E/F fraction also contains TFIIH (Flores et al. 1992). Expression and partial purification of the recombinant TFIIB from E. coli were as described (Ha et al. 1991). Oligonucleotide T35570 5' -ACACCACTCGACACGGCA-3' was used for primer extension assays of transcription from plasmids $\mathrm{pG}_{5} \mathrm{E} 4 \mathrm{~T}$ and $\mathrm{pZ} \mathrm{F}_{7} \mathrm{E} 4 \mathrm{~T}$. Primer SP6 5'-ATTTAGGTGACACTATAGAACTCGAGCAG- 3 ' was used for primer extension assays for transcripts from plasmid VI.

\section{DNA-binding assays}

DNase I cleavage inhibition (footprinting) by the affinity-purified eTFIID complex and recombinant eTBP protein were assayed as described previously (Schmidt et al. 1989). The footprinting probe used in the study contained the adenovirus type 2 major late promoter DNA sequences from -66 to +33 inserted into the pUC18 polylinker. It was generated by end-labeling plasmids pUML-1 (W.S. Lee and A.J. Berk, unpubl.) at the HindIII site $(+70$ relative to the transcription start site) by Klenow reaction and then cutting with $N d e$ I to generate a $365-b p$ fragment. Alternatively, DNA-protein complexes were analyzed by native gel electrophoresis (EMSA) as described (Lieberman and Berk 1991), using a DNA fragment containing the adenovirus type 2 early $1 B$ promoter region. The top-strand sequence of the three oligonucleotides used in the competition experiment (Fig. 5B) were TATA, 5'-TCGACTTAAAGGGTATATAATGCGCCGTG-3' ; ZRE, 5'-GATCTTCTAGACCAAATGTGCAAAGGTGAG- ${ }^{\prime}$; , and TACA, 5' ${ }^{\prime}$ TCGACTTAAAGGGTACATAATGCGCCGTG-3'.

\section{Sedimentation velocity centrifugation}

The affinity-purified eTFIID complex $(200 \mu \mathrm{l})$ was layered on a $10-30 \%$ sucrose gradient made in $0.5 \mathrm{M} \mathrm{KCl} \mathrm{D}$ buffer and centrifuged in an SW50.1 rotor at $45,000 \mathrm{rpm}$ for $13 \mathrm{hr}$ at $4^{\circ} \mathrm{C}$. The gradient was dripped into 17 fractions that were TCA precipitated, as described (Peterson 1977), and subjected to SDS-PAGE and analyzed by silver staining. The $0.5-1.0 \mathrm{M} \mathrm{KCl}$ phosphocellulose fraction (fraction D, $100 \mu$ l) of the LTR $\alpha 3$ nuclear extract containing eTFIID was run in a parallel gradient. Fractions were precipitated with TCA, subjected to SDS-PAGE, and blotted onto nitrocellulose. The Western procedure was then performed with mAb $12 \mathrm{CA} 5$ to detect eTBP protein.

\section{Acknowledgments}

This work was supported by U.S. Public Health Service grant CA 25235. P.M.L. is supported by a grant from the Leukemia Society, and T.G.B. by a grant from the American Cancer Society.

The publication costs of this article were defrayed in part by payment of page charges. This article must therefore be hereby marked "advertisement" in accordance with 18 USC section 1734 solely to indicate this fact.

\section{References}

Buratowski, S.P., S. Hahn, L. Guarente, and P.A. Sharp. 1989. Five intermediate complexes in transcription initiation by RNA polymerase II. Cell 56: 549-561.

Carey, M., Y.-S. Lin, M.R. Green, and M. Ptashne. 1990. A mechanism of synergistic activation of a mammalian gene by GAL4 derivatives. Nature 345: 361-364.

Chang, Y.-N., D.L.-Y. Dong, G.S. Hayward, and D.S. Hayward. 1990. The Epstein-Barr virus Zta transactivator: A member of the bZIP family with unique DNA-binding specificity and a dimerization domain that lacks the characteristic heptad leucine zipper motif. J. Virol. 64: 3358-3369.

Comai, L., N. Tanese, and R. Tjian. 1992. The TATA-binding protein and associated factors are integral components of the RNA polymerase I transcription factor, SL1. Cell 68: 965976.

Conoway, J.W., J.P. Hanley, K.P. Garrett, and R.C. Conoway. 1991. Transcription initiated by RNA polymerase II and transcription factors from liver. Structure and action of tran- 
scription factors $\epsilon$ and $\tau$. J. Biol. Chem. 266: 7804-7811.

Cormack, B.P. and K. Struhl. 1992. The TATA-binding protein is required for transcription by all three nuclear RNA polymerases in yeast cells. Cell 69: 685-696.

Cortes, P., O. Flores, and D. Reinberg. 1992. Factors involved in transcription by mammalian RNA polymerase II: Purification and analysis of transcription factor IIA and identification of transcription factor IIJ. Mol. Cell. Biol. 12: 413-421.

Dignam, J.D., R.M. Lebovitz, and R.G. Roeder. 1983. Accurate transcription initiation by RNA polymerase II in a soluble extract from isolated mammalian nuclei. Nucleic Acids Res. 11: $1475-1489$.

Dynlacht, B.D., T. Hoey, and R. Tjian. 1991. Isolation of coactivators associated with the TATA-binding protein that mediate transcriptional activation. Cell 66: 563-576.

Farrell, P.J., D.T. Rowe, C.M. Rooney, and T. Kouzarides. 1989. Epstein-Barr virus BZLF1 trans-activator binds to consensus AP-1 site and is related to c-fos. EMBO /. 8: 127-132.

Field, J., J.-I. Nikawa, D. Broek, B. MacDonald, L. Rodgers, I.A. Wilson, R.A. Lerner, and M. Wigler. 1988. Purification of a ras-responsive adenyl cyclase complex from Saccharomyces cerevisiae by use of an epitope addition method. Mol. Cell. Biol. 8: 2159-2165.

Flemington, E. and S.H. Speck. 1990. Evidence for coiled-coil dimer formation by an Epstein-Barr virus transactivator that lacks a heptad repeat of leucine residues. Proc. Natl. Acad. Sci. 87: 9459-9463.

Flores, O., H. Lu, and D. Reinberg. 1992. Factors involved in specific transcription initiation by mammalian RNA polymerase II. Identification and characterization of factor IIH. $J$. Biol. Chem. 267: 2786-2793.

Giniger, E. and M. Ptashne. 1987. Transcription in yeast activated by a putative amphipathic $\alpha$ helix linked to a DNA binding unit. Nature 330: 670-672.

Giot, J.-F, I. Mikaelian, M. Buisson, E. Manet, I. Jaob, J.-C. Nicolas, and A. Sergeant. 1991. Transcriptional interference between the EBV transcriptional factors EB1 and R: Both DNAbinding and activation domains of $\mathrm{EB} 1$ are required. Nucleic Acids Res. 19: 1251-1258.

Graham, F.L. and A.J. van der Eb. 1973. A new technique for the assay of infectivity of human adenovirus 5 DNA. Virology 52: 456-467.

Ha, I., W.S. Lane, and D. Reinberg. 1991. Cloning of a human gene encoding the general transcription factor IIB. Nature 352: 689-695.

Harlow, E. and D. Lane. 1988. Antibodies: A laboratory manual. Cold Spring Harbor Laboratory, Cold Spring Harbor, New York.

Hoffmann, A., E. Sinn, T. Yamamoto, J. Wang, A. Roy, M. Horikoshi, and R.G. Roeder. 1990. Highly conserved core domain and unique $\mathrm{N}$ terminus with presumptive regulatory motifs in a human TATA factor (TFIID). Nature 346: 387-390.

Horikoshi, N., K. Maguire, A. Kralli, E. Maldonado, D. Reinberg, and R. Weinman. 1991. Direct interaction between adenovirus ElA protein and the TATA box binding transcription factor IID. Proc. Natl. Acad. Sci. 88: 5124-5128.

Ingles, C.J., M. Shales, W.D. Cress, S.J. Triezenberg, and J. Greenblatt. 1991. Reduced binding of TFIID to transcriptionally compromised mutants of VP16. Nature 351: 588-590.

Kadonaga, J. and R. Tjian. 1986. Affinity purification of sequence-specific DNA binding proteins. Proc. Natl. Acad. Sci. 83: 5889-5893.

Kadonaga, J., K.R. Carner, F.R. Masiarz, and R. Tjian. 1987. Isolation of a cDNA encoding transcription factor $\mathrm{Sp} 1$ and functional analysis of the DNA binding domain. Cell 42: 559572.
Kao, C.C., P.M. Lieberman, M.C. Schmidt, Q. Zhou, R. Pei, and A.J. Berk. 1990. Cloning a transcriptionally active human TATA binding factor. Science 248: 1646-1650.

Lee, K.A.W., A. Bindereif, and M.R. Green. 1988. A small-scale procedure for preparation of nuclear extracts that support efficient transcription and pre-mRNA splicing. Gene Anal. Tech. 5: 22-31.

Lee, W.S., C.C. Kao, G.O. Bryant, and A.J. Berk. 1991. Adenovirus $\mathrm{E} 1 \mathrm{~A}$ activation domain binds the basic repeat in the TATA box transcription factor. Cell 67: 365-376.

Lieberman, P.M. and A.J. Berk. 1990. In vitro transcriptional activation, dimerization and DNA-binding specificity of the Epstein-Barr virus Zta protein. J. Virol. 64: 2560-2568.

- 1991. The Zta trans-activator protein stabilizes TFIID association with promoter DNA by direct protein-protein interaction. Genes \& Dev. 5: 2441-2454.

Lillie, J.W. and M.R. Green. 1989. Transcription activation by the adenovirus Ela protein. Nature 338: 39-44.

Lin, Y.-S. and M.R. Green. 1991. Mechanism of action of an acidic transcriptional activator in vitro. Cell 64: 971-981.

Martin, K.J., J.W. Lillie, and M.R. Green. 1990. Evidence for interaction of different eukaryotic transcriptional activators with distinct cellular targets. Nature 346: 147-152.

Meisterenst, M. and R.G. Roeder. 1991. Family of proteins that interact with TFIID and regulate promoter activity. Cell 67: 557-567.

Meisterenst, M., A.L. Roy, H.M. Lieu, and R.G. Roeder. 1991. Activation of regulatory gene transcription by regulatory factors is potentiated by a novel activity. Cell 66: 981-994.

Miller, A.D. and G.J. Rosman. 1989. Improved retroviral vectors for gene transfer and expression. BioTechniques 7: 980-990.

Muller, A.J., J.C. Young, A.M. Pendergast, M. Pondel, N.R. Landau, D.R. Littman, and O.N. Witte. 1991. BCR first exon sequences specifically activate $B C R / A B L$ tyrosine kinase oncogene of Philadelphia chromosome-positive human leukemias. Mol. Cell. Biol. 11: 1785-1792.

Nakajima, N., M. Horikoshi, and R.G. Roeder. 1988. Factors involved in specific transcription by mammalian RNA polymerase II: Purification, genetic specificity, and TATA-box promoter interactions of TFIID. Mol. Cell. Biol. 8: 40284040.

Peterson, G.L. 1977. A simplication of the protein assay method of Lowry et al. which is more generally applicable. Analyt. Biochem. 83: 346-356.

Peterson, M.G., N. Tanese, B.F. Pugh, and R. Tjian. 1990. Functional domains and upstream activation properties of cloned human TATA binding protein. Science 248: 1625-1630.

Ptashne, M. 1986. A genetic switch. Gene control and phage $\lambda$. Blackwell Scientific Publications \& Cell Press, Cambridge, MA.

Pugh, B.F. and R. Tjian. 1990. Mechanism of transcriptional activation by Spl: Evidence for coactivators. Cell 61: 11871197.

- 1991. Transcription from a TATA-less promoter requires a multisubunit TFID complex. Genes \& Dev. 5: 1935-1945.

- 1992. Diverse transcriptional functions of the multisubunit eukaryotic TFIID complex. I. Biol. Chem. 267: 679682.

Samuels, M., A. Fire, and P.A. Sharp. 1982. Separation and characterization of factors mediating accurate transcription by RNA polymerase II. J. Biol. Chem. 257: 14419-14427.

Sawadogo, M. and R.G. Roeder. 1985. Interaction of a genespecific transcription factor with the adenovirus major late promoter upstream of the TATA-box region. Cell 43: 165175. 
Schmidt, M.C., Q. Zhou, and A.J. Berk. 1989. Spl activates transcription without affecting the DNA binding activity of the TATA box factor. Mol. Cell. Biol. 9: 3299-3307.

Schultz, M.C., R.H. Reeder, and S. Hahn. 1992. The TATA binding protein is essential for transcription by RNA polymerase I, II, and III: Variants which distinguish different subset of nuclear promoters. Cell 69: 697-702.

Sharp, P.A. 1992. TATA binding protein is a classless factor. Cell 68: 819-821.

Smale, S.T. and D. Baltimore. 1989. The "initiator" as a transcription control element. Cell 57: 103-113.

Smale, S.T., M.C. Schmidt, A.J. Berk, and D. Baltimore. 1990. Transcription activation by $\mathrm{Spl}$ as directed through TATA or initiator: Specific requirement for mammalian transcription factor IID. Proc. Natl. Acad. Sci. 87: 4509-4513.

Stringer, K.F., C.J. Ingles, and J. Greenblatt. 1990. Direct and selective binding of an acidic transcriptional activation domain to the TATA-box factor TFIID. Nature 345: 783-786.

Tanese, N., B.F. Pugh, and R. Tjian. 1991. Coactivators for a proline activator purified from the multisubunit human TFIID complex. Genes \& Dev. 5: 2212-2224.

Van Dyke, M.W., R.G. Roeder, and M. Sawadogo. 1988. Physical analysis of transcription preinitiation complex assembly on a class II gene promoter. Science 241: 1335-1338.

Webster, L.C. and R.P. Ricciardi. 1991. Trans-dominant mutants of ElA provide genetic evidence that the zinc finger of the trans-activating domain binds a transcription factor. Mol. Cell. Biol. 11: 4287-4296.

White, R.J., S.P. Jackson, and P.W.J. Rigby. 1992. A role for the TATA-box-binding protein component of the transcription factor IID complex as a general RNA polymerase III transcription factor. Proc. Natl. Acad. Sci. 89: 1949-1953. 


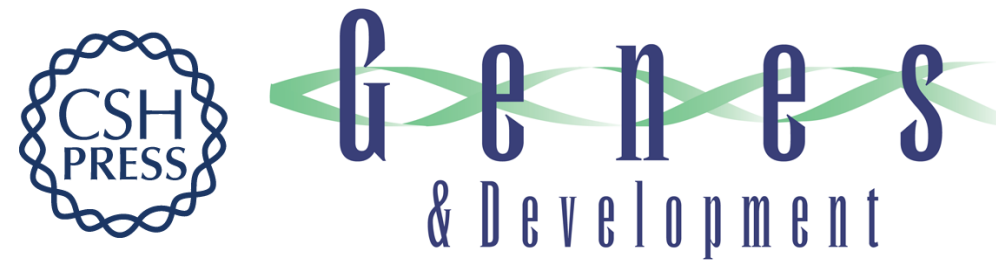

\section{Holo-TFIID supports transcriptional stimulation by diverse activators and from a TATA-less promoter.}

Q Zhou, P M Lieberman, T G Boyer, et al.

Genes Dev. 1992, 6:

Access the most recent version at doi:10.1101/gad.6.10.1964

References This article cites 52 articles, 23 of which can be accessed free at:

http://genesdev.cshlp.org/content/6/10/1964.full.html\#ref-list-1

License

Email Alerting

Service

Receive free email alerts when new articles cite this article - sign up in the box at the top right corner of the article or click here.

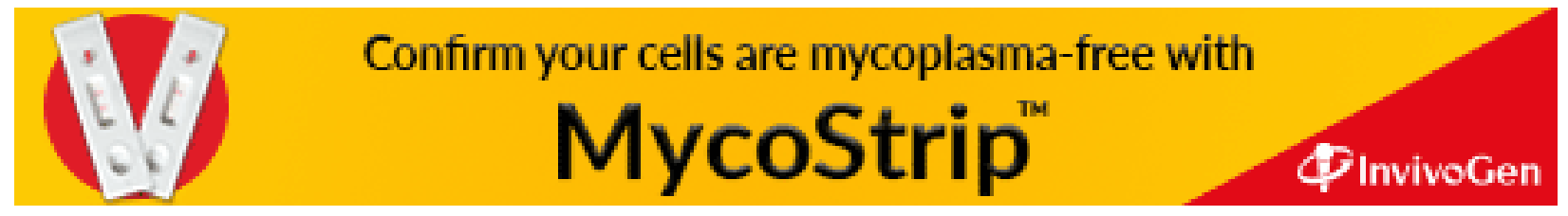

